\title{
NOTA
}

\section{Ell principio de El ingenioso hidalgo don Quijote de la Mancha}

\author{
Antonio González Montes \\ Universidad Nacional Mayor de San Mercos
}

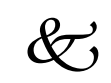

Hingenioso hidalgo don Quijote de la Mancha (1605) de Miguel de $H_{\text {Cervantes (1547-1616) es una dora de lectura imprescindible para }}$ todo hablante del idioma español. Por haber sido publicada hace cuatrocientos años, el acceso al mundo inolvidable de la novela se nos hace más fácil si contamos con una edición que nos guíe con sabiduría y discreción por las páginas gloriosas de esta magna creación del genio cervantino. Esa función es la que cumple, por ejemplo, la preparada por Martín de Riquer ${ }^{1}$, insigne especialista en la novela española por antonomasia, y en cuyo nombre rendimos homenaje a todos aquellos estudiosos que se han dedicado a la tarea ingente de perpetuar la presencia impresa del quijote entre los lectores de todas las épocas y de todas las sociedades que recorren admirados las andanzas del famoso hidalgo manchego y de todos los personajes que lo rodean y lo complementan, entre ellos, el singular Sancho Panza, par irremplazable del protagonista más universal de las letras castellanas.

Estas líneas introductorias tratan de justificar la osadía nuestra de pretender analizar una breve porción de la obra (los cinco primeros capítulos de la primera parte). Empero, las observaciones están hechas más desde la óptica del simple lector que la del especialista que hace gala, con todo derecho, de erudición y de seguridad en el manejo del texto en su totalidad. En nuestro caso, la elección del dbjeto de estudio (los citados cinco primeros capítulos) se debió a la comprobación personal de que esta parte constituye una suerte de mundo pequeño, con una 
cierta independencia, dentro del universo total de la novela. En verdad, como lo ha afirmado la crítica, la unidad gldbal del libro es indiscutible y constituye una prueba fehaciente de la maestría y perfección de la vasta creación cervantina, lo que no impide en la práctica que el lector se pueda detener o limitar a apreciar y valorar algunos capítulos de esta obra que hoy celebra 400 años de vida plena y dialógica.

Nuestro criterio es que los citados capítulos iniciales pueden leerse como una sola secuencia, la cual ofrece un efecto de circularidad, pues las páginas que la constituyen presentan al protagonista desde su nacimiento literario, entre los ambientes de su casa manchega, hasta su retorno a la misma, luego de haber salido a recorrer el mundo circundante para hacerse reconocer como «caballero andantes y actuar como tal en el plano de la singular y ariosa realidad («la caballeresca») que el personaje logra inconporar dentro de la realidad concreta en la que se desenvuelven todos los seres que rodean al Quijote. En otras palabras, los cinco capítulos prueban la competencia ficcional del protagonista, pues demuestran que este loco insólito es capaz de llevar al plano de la realidad todas aquellas vivencias, convicciones y actos que son el elemento constitutivo de su condición anacrónica de «caballero andante».

En función de este gran abjetivo del narrador, los cinco capítulos cumplen cometidos muy precisos con vistas a lograr imponer a este protagonista único en el ámbito complejo y difícil de la acción misma, de modo que aun de modo disparatado transforme la realidad y obligue a los personajes que lo acompañan a aceptar su existencia y sus modos de actuar, los cuales están motivados por su propósito de conducirse como un «caballero andante» en el contexto de una sociedad que consideraba como un evidente anacronismo a un personaje como éste. De acuerdo a este ambicioso propósito creativo, cada uno de los capítulos posee una velocidad, un ritmo y una técnica diferentes, los que trataremos de mostrar a través de una lectura que se centra, sobre todo, en la percepción de la evolución mental y discursiva del protagonista y en la observación de ciertos episodios que ilustran el estilo de interacción del auijote y la reacción de aquellos que lo rodean.

Así, el célebre capítulo I «Que trata de la condición y ejercicio del famoso hidalgo don Quijote la Mancha» enfoca el espacio de la casa 
del protagonista y permite apreciar, desole dentro, el lento proceso a través del cual el pacífico lugareño Quijana se convierte en el inquieto «caballero andante» don Quijote, que saldrá a realizar todas aquellas acciones de bien que son propias de este oficio. El camino, sin duda, no es rápido ni sencillo, pero las fuentes «autorizadas» e insustituibles para llevar adelante este curioso proceso de conversión son las novelas de caballería, libros que el dueño de casa lee con fruición y obsesión, lo cual produce un cambio profundo en su personalidad y lo lleva a concebir un proyecto vital que el narrador considera disparatado, irreal y fuera de época. Pero el aspirante a «caballero andante» no ceja en su propósito y al término de este capítulo lo vemos «transformado» tanto en el plano mental, como en el del lenguaje y en el de la apariencia exterior, y dispuesto a pasar al plano de la acción en el mundo circundante. De modo, pues, que el capítulo I muestra con precisión y detalle el proceso de auto transformación que lleva a cabo el personaje para dejar de ser lo que era (Quijana) y llegar a ser lo que su fuero íntimo anhela con toda la fuerza de su obsesiva locura.

El capítulo II, «Que trata de la primera salida que de su tierra hizo el ingenioso don Quijote» y el III, «Donde se cuenta la graciosa manera que tuvo don quijote en armarse caballero», guardan una estrecha relación y pueden ser considerados como un núcleo muy importante dentro del pequeño universo que estamos analizando. En efecto, en el espacio textual de dichos capítulas el protaganista da pasas decisivas y definitivos dentro de su proyecto de ser y actuar como un caballero andante. Para ello, no hay más remedio que salir al mundo y enfrentarse a la realidad, pues es en ella donde el héroe debe plasmar con acciones su hacer caballeresco. Y don Quijote se dirige resuelto a enfrentarse con su destino, aunque sabe que es indispensable ser armado caballero. Esa será la acción central que se cumpla en el transcurrir de ambos capítulos, pues don Quijote se cree y se sabe caballero, pero es de rigor que se cumpla el ritual de reconocimiento de su condición, a fin de que él pueda salir a amplir su misión provisto de toolos los requisitos que exige este noble e ilustre oficio. Aun antes de encontrarse con alguien que celebre la ceremonia respectiva, el personaje piensa en la fama de la que gozará y en la historia que algún sabio escribirá sobre sus aventuras. 
En este contexto es de destacar la emergencia de la primera voz del narrador para darnos a conocer lo que ha podido averiguar acerca de las acciones iniciales que protagonizó don quijote. Dichas acciones tienen como escenario la famosa venta en la que el aspirante a caballero recibió el espaldarazo respectivo para poder ser tal. Ias escenas que muestran la llegada y la instalación del personaje en el citado lugar permiten constatar su locura galopante, pues confunde a la venta con un castillo y a las mozas que estaban en dicho lugar con dos damas distinguidas. Mas no sólo su percepción se engaña, sino que también su lenguaje demuestra el desfase verbal que aqueja al protagonista, quien habla a las mozas con una norma lingüística que ya en ese momento era arcaica, motivo por el cual las jóvenes no entienden el lenguaje del quijote y se echan a reír.

Un personaje clave en estos pasajes es el del ventero, pues éste se da cuenta de la locura de su huésped y pese a ello acepta entrar en el juego que éste le propone. Esta decisión es clave para toob el desarrollo posterior de la novela, pues, como se pregunta Martín de Riquer: ¿Qué hubiera ocurrido si este personaje se negaba a llevar a cabo lo que se le estaba pidiendo? Allí hubiera concluido la acción o se hubiera encaminado dentro de los muchos posibles narrativos, pero Cervantes decidió que el ventero asintiera al extraño pedido que le hacía al recién llegado y con ello desencadenó la vasta narración que caracteriza al libro de 1605.

Es en el capítulo III donde se realiza el ceremonial caballeresco, que está precedido por una serie de hechos que confirman, una vez más, la extraña conducta del protagonista, la cual es conocida y compartida por casi todos los que están alojados en dicho lugar, con excepción de unos arrieros, quienes ignorantes del ritual que está cumpliendo el inminente caballero, botan las armas de su lugar para poder dar agua a sus animales. Estas sacrílegas acciones son castigadas por el Quijote, lo que origina la reacción de los compañeros de los agredidos y también la irrupción de una atmósfera de violencia y de pendencia frecuente en la secuencia que comentamos. Es de destacar que, por primera vez, el protagonista se encomienda a su dama, Dulcinea del Toboso, para impulsar su propósito de sanción. La descripción de la ceremonia con que se cierra el capítulo es muy 
sugestiva y no está exenta de ironía hacia el flamante apadrinado. Al mismo tiempo, la observación de los hechos lleva a concluir que coexisten en el relato dos actitudes ante la realidad: la del ventero, las mozas, los arrieros y demás inquilinos de la venta que puede ser tipificada como la pasición realista, prosaica, pedestre, y, por otro lado, la de don Quijote, actitud alucinada, fantasiosa, idealizante que trata de imponerse a la primera. Y es gracias a ese sabio narrador que entreteje el contrapunto de las cosmovisiones que los lectores podemos gozar con los choques que a cada momento ocurren en el desarrollo de trama novelesca. Pero el narrador, si bien se sonríe con las excentricidades de su personaje, lo sigue fielmente y nos confirma que al término de toob este ajetreo de la ceremonia, ya tenemos los lectores a un caballero andante a carta cabal y debemos disponemos a verlo en acción en seguida.

El capítulo IV, «De lo que le sucedió a nuestro caballero cuando salió de la venta», concentrado y armonioso, como casi todo lo que salió de la pluma de Cervantes, satisface con creces nuestro deseo de gozar y de sufrir con las incomparables aventuras de don Quijote. A diferencia de los capítulos inmediatamente anteriores, que desarrollan en la práctica un solo gran suceso (la ceremonia del espaldarazo) , por supuesto con sus indispensables prolegómenos, el capítulo IV nos obsequia con dos extraordinarias anécdotas, independientes la una de la otra, y que tienen la virtud de mostrarnos las dos grandes razones por las cuales combate a brazo partido el invicto protagonista manchego: la justicia y el amor.

Veamos: después de abandonar el ámbito de la venta (para él, casti ilo) don Quijote, siguiendo los consejos de su padrino el ventero, decide regresar a su casa para aprovisionarse de dinero y conseguir un escudero, mas en el camino se encuentra con situaciones que le permiten estrenar su flamante condición de caballero. Ell primer episodio es el del labrador que propina azotes a un mozo que trabaja con él. La escena es para don Quijote un ejemplo patente de un entuerto que hay que desfacer, y para ello nadie mejor que él, que acaba de ser investido con los signos propios del caballero andante. Ia razón por la cual él se siente con derecho a terciar en este incidente es porque desole la óptica de su noble oficio entiende que debe restablecer la justicia en el mundo y 
para ello es necesario castigar a quien abusa de su poder y proteger a quien a causa de su inferioridad o debilidad es incapaz de defenderse por sí mismo de los atropellos que sufre.

Es insuperable el modo en que Cervantes muestra la interrelación entre los tres personajes que protagonizan el conflicto. Así, el labrador a través de sus palabras se nos revela como un sujeto perverso, ladino, cruel, falso. A su vez, don Quijote sorprende por su habilidad para argumentar bien y desbaratar de ese modo las estratagemas del labrador, pero al mismo tiempo nos decepciona con su ingenuidad, pues cree en lo que le dice su interlocitor, aunque el narrador y los lectores sabemos que no cumplirá con su promesa de pagar la deuda al muchacho a quien había estadb castigandb hasta antes de la llegada del paladín de la justicia. La joven víctima del abuso, en cambio, analiza el problema que está viviendo con sensatez y madurez. Sabe que el labrador le está mintiendo a don Quijote y se lo dice a éste, pero muestro crédulo caballero piensa que su nombre y autoridad serán suficientes para atemorizar al agresor y hacer que cumpla con lo prometido.

Después de haber desbaratado el entuerto, según cree, el de la triste figura se marcha del escenario donde acaba de protagonizar su primera acción memorable como miembro de la orden de la caballería. El narrador lo deja ir momentáneamente para hacemos ver el primer fracaso del amo de Rocinante, pues ni bien desaparecen jinete y caballo, el labrador toma a amarrar al joven para darle más azotes y dice con ironía que va a cumplir con su palabra, pero que para aumentar la paga quiere aumentar la deuda y por ello hace llover más azotes. El narrador retoma a su criatura para sorprenderlo en el momento en el que en su fuero íntimo piensa, con mucho orgullo, que acaba de realizar una extraordinaria hazaña de la que, sin duda, hablarán y escribirán los historiadores. Y no le faltaba razón o sinrazón. Este suceso muestra también la genial habilidad de Cervantes para diseñar la escena y desenvolver el diálogo. Nada sobra, nada falta; toob está en su sitio, y el lector no tiene sino que seguir con admiración la prosa mágica del maestro de la lengua española. Podríamos agregar que aquí también asistimos al contraste entre conductas de los personajes: las extremas son las del labrador (abusivo, cobarde, falso) y la de dan Quijote (crédulo, ingenu) . El equilibrio y la sensatez están representadbs por el muchacho 
que tiene el doloroso privilegio de ser el primer individuo «salvado» de las garras del abuso y de la violencia por el flamante caballero.

El capítulo IV aún nos tiene reservado otro episodio en el que el protagonista nos hace saber con las palabras de la acción que no sólo combate por la causa de la justicia, sino por la del amor a su dama, como corresponde a todo buen miembro del género y de la orden. Nos referimos a su enfrentamiento con los mercaderes toledanos a quienes él tiene por caballeros. En estas escenas, el singular lenguaje de don quijote es el desencadenante del conflicto creado, pues los viajeros son conminados a declarar su admiración a la belleza de Dulcinea, a quien, sin duda, no han visto nunca. Esta insólita y disparatada petición da pie para que uno de los personajes se trabe en una acalorada discusión con el peticionario, pues, como afirma con sentido común, no puede reconocer la belleza de Dulcinea si no la conoce y por ello pide un retrato o alguna prueba que permita inferir la perfección de aquélla. La réplica de don Quijote no deja de tener resonancias filosóficas y religiosas pues con toda seriedad y convicción sostiene que deben creer en la belleza de Dulcinea aun sin conocerla.

Como es de prever, los participantes de tan acalorado y polémico diálogo no se ponen de acuerdo, sobre todo porque el viajero que hizo de interlocutor no sólo no reconoce los méritos de la dama sino que se burla con crueldad y ensañamiento. Don quijote no puede sufrir tamaña afrenta a su musa y pasa al plano de la acción física: arremete contra su opositor para castigar su osadía y atrevimiento. Pero esta vez también fracasa, como en el episodio anterior, pues Rocinante tropieza y cae y con él su descalabrado amo. La desgracia del protagonista no acaba allí: uno de los que son parte de los caminantes se irrita por las impert inencias que escucha decir al maltrecho personaje y le propina una tunda tal que don Quijote queda apaleado igual que el mozo a quien «libró» de los abusos del labradon». Este final muestra el muevo fracaso del protagonista y se suma al primero en la mente de los lectores, pero no en la del «caballero», pues este no sabe que el labrador se burló de su promesa y siguió maltratando al supuesto liberado. Ambos sucesos i lustran la distancia entre el deseo y la realidad, pero don Quijote no se amilanará por estas pequeñas y para él transitorias derrotas. 
El capítulo V, «Donde se prosigue la narración de la desgracia de muestro caballero» muestra, precisamente, el estado calamitoso en que ha quedado el protagonista, como consecuencia de la paliza recibida. Lo crucial es que está imposibilitado de moverse y por tanto de seguir su recorrido de retomo a casa; en ese trance se imagina ser otro personaje y comienza a delirar una serie de impertinencias, pero esta cháchara constituye su tabla de salvación pues un personaje que pasaba cerca de allí lo escucha desvariar y se acerca a él. Para suerte del descalabrado, dicho personaje es Pedro Alonso su vecino, lo reconoce como el señor Quijana y lo lleva de vuelta a casa. Al retomar el labrador vecino tiene la oportunidad de apreciar la locura total del malherido personaje pues no sólo cree ser otro, sino que a su salvador lo confunde con otro ser que por supuesto existe en el mundo ficticio de las novelas de caballería.

Don Pedro Alonso se toma el trabajo de llevar de vuelta a su casa al héroe vencido y este se encuentra en estado tan lamentable que no puede recorrer el camino sobre la montura de Rocinante, y tiene que hacerlo tendido en las ancas de un jumento. En su hogar lo esperan el ama, su sobrina, y sus amigos, el cura y el barbero. Todos coinciden en que la causa de la locura del personaje son los libros de caballería y como ocurrirá en el siguiente capítulo, dichos libros pagarán su culpa y serán quemados después de un escrutinio que distingue la paja del trigo.

Este capítulo V se relaciona con el I y se cierra como un primer círculo que muestra la primera salida que ha realizado el protagonista. Dicho recorrido es el primero de otros que realizará en las siguientes páginas. Pero este primer periplo nos ha permitido conocer lo que será en esencia el accionar del Quijote: una lucha desigual en la que siempre será vencido, lo cual no le impedirá recobrar bríos para acometer, cual nuevo Sísifo, la batalla de todos los días contra la implacable y traidbra realidad, con la esperanza de alcanzar una victoria. Victoria que ya dura cuatrocientos años.

\section{Nota}

1 Miguel de Cervantes. El Ingenioso Hidalgo don Quijote de la Mencha. Edición, Introducción y Notas de Martín de Riquer de la Real Academia Española. Editorial Planeta, España, 1999. 